\title{
MOVIMENTO SOCIAL E A EDUCAÇÃO: O ENSINO MÉDIO NA ESCOLA CRESCENDO NA PRÁTICA ${ }^{1}$
}

\section{Larissa de Nazaré Carvalho de Aviz²}

\begin{abstract}
Resumo $^{3}$
Resulta de uma pesquisa que teve como objetivo analisar o processo de escolarização no Ensino Médio de jovens filhos dos trabalhadores pertencentes ao assentamento Palmares II, na Amazônia paraense. Versa em sua fundamentação teórica sobre os estudos de Caldart (2007), Laureano (2007) e Grzybowski (1991), tendo como referencial o materialismo histórico-dialético. Demonstra que o Ensino Médio conquistado pelo MST vem perdendo sua identidade, pois o currículo proposto fragiliza os saberes constituídos na vivência do movimento social.

Palavras-chave: Movimento dos Trabalhadores Sem Terra; Ensino Médio; Juventude da classe trabalhadora.

\section{MOVIMIENTO SOCIAL LA EDUCACIÓN: EN LA ENSEÑANZA MEDIA DE LA ESCUELA CRESCENDO NA PRÁTICA}

\section{Resumen}

Resulta de una investigación dirigida a analizar el proceso de escolarización en la escuela secundaria de niños de trabajadores pertenecientes al asentamiento de Palmares II, en la Amazonía de Pará. Discute en su fundamento teórico los estudios de Caldart (2007), Laureano (2007) y Grzybowski (1991), utilizando el materialismo histórico-dialéctico como referencia. Demuestra que la escuela secundaria ganada por el MST ha estado perdiendo su identidad, ya que el plan de estudios propuesto debilita el conocimiento constituido en la experiencia del movimiento social.

Palabra chave: Movimiento de Trabajadores Sin Tierra; Escuela secundaria; Juventud de clase trabajadora.

\section{SOCIAL MOVEMENT AND EDUCATION: IN HIGH SCHOOL OF THE SCHOOL CRESCENDO NA PRÁTICA}

\begin{abstract}
Results from a research that aimed to analyze the process of schooling in high school of young children of workers belonging to the Palmares II settlement, in the Amazon of Pará. It's theoretical foundation is based on the studies of Caldart (2007), Laureano (2007) and Grzybowski (1991), using historical-dialectical materialism as a reference. It demonstrates that the High School won by the MST has been losing its identity, as the proposed curriculum weakens the knowledge constituted in the experience of the social movement.
\end{abstract}

Keyword: Landless Workers Movement; High school; Working class youth.

\footnotetext{
${ }^{1}$ Artigo recebido em 29/04/2020. Primeira Avaliação em 30/05/2020. Segunda Avaliação em 04/06/2020. Aprovado em 23/08/2020. Publicado em 25/09/2020.

DOI: DOI: https://doi.org/10.22409/tn.v18i37.42430.

${ }^{2}$ Professora da Universidade do Estado do Pará (UEPA); Mestra em Educação pelo Programa de Pós-Graduação em Educação da Universidade do Estado do Pará (PPGED/UFPA); Membro do Grupo de Estudos e Pesquisas sobre Trabalho e Educação da Universidade Federal do Pará (GEPTE/UFPA). E-mail: larissaviz@gmail.com ORCID: 0000-0002-5255-545X.

Lattes: http://lattes.cnpq.br/1981446092851473

${ }^{3}$ Uma primeira versão deste trabalho foi apresentada no VI Colóquio Nacional Trabalho, Educação e Resistência em comunidades e povos tradicionais, realizado no período de 06 a 08 de novembro de 2019, no Campus Universitário do Baixo Tocantins, da Universidade Federal do Pará (UFPA), sendo esta uma versão revista e ampliada.
} 


\section{Introdução}

Movimento social e a educação na Amazônia Paraense: o Ensino Médio da Escola Crescendo na Prática é o título deste artigo, que nasce com a finalidade de apresentar, a partir de uma perspectiva dialética, o sentido do Ensino Médio para os jovens da classe trabalhadora do assentamento Palmares II.

As reflexões aqui apresentadas fazem parte da pesquisa de mestrado (20142016) que teve como objetivo analisar a integração/fragmentação entre os saberes sociais produzidos por jovens do assentamento Palmares II e os conhecimentos escolares, na perspectiva da luta de classes, no contexto educacional do Ensino Médio da Escola Crescendo na Prática, no município de Parauapebas (PA).

A Escola Crescendo na Prática e, dentro dela, o Ensino Médio constituem o espaço da educação escolar de jovens e adultos do assentamento Palmares II, no Sudeste do Pará. Reconhecido, entretanto, que, nesse lugar, as características que demarcam o movimento social - neste caso, o Movimento dos Trabalhadores Sem Terra (MST) - para além do campo formal, as práticas educativas evidenciadas pela produção e formação dos sujeitos encontra campo fértil para a conjugação.

Sobre isso, Arroyo (2002) compreende que a escola não é o único espaço que detém a educação, assinalando que o meio social contribui proficuamente para a formação do indivíduo e, ainda, que é por meio das relações sociais que se constituem as apropriações dos saberes.

Dessa maneira, é possível compreender a distinção entre a educação entendida enquanto instrução e a educação entendida enquanto produçãoformação dos sujeitos, no que tange à construção da identidade de uma classe, uma movimentação que cerca a ação escolar como elemento que permite serem acrescentadas novas dimensões às ações desenvolvidas, e que, por sua vez, enriquecem as anteriores, atendendo aos interesses de classe (SAVIANI, 1996).

Ressaltamos que a Escola Crescendo na Prática, entre 2005 e 2013, apresentava sua base curricular vinculada ao Ensino Médio modular, e só em 2014 começou a trabalhar com a matriz do Ensino Médio regular.

Com o fim de analisar o que dizem os relatos dos sujeitos pesquisados, apresentamos os dados coletados por meio da realização de entrevistas semiestruturadas, nas quais foi possível viabilizar as categorias a serem descritas 
como fenômenos sociais. A entrevista é uma das principais técnicas de pesquisa e desempenha um importante papel, não apenas nas atividades científicas, como em muitas outras. Por esta técnica de coleta de dados, há interação entre pesquisador e entrevistado (LUDKE; ANDRÉ, 2003, p. 33).

Com base nessa compreensão, as entrevistas foram aplicadas na Escola Crescendo na Prática no decorrer do mês de maio de 2015. Foram realizadas em dois momentos: o primeiro, com um grupo de 12 (doze) jovens que foi entrevistado por cerca de 50 minutos, com o objetivo de selecionar os respondentes da entrevista que focou nas questões norteadoras da pesquisa; e, no segundo, foram entrevistados 05 (cinco) jovens sujeitos selecionados deste universo de 12 alunos, 03 (três) rapazes e 02 (duas) moças (A1, A2, A3, A4 e A5), bem como o Coordenador do Ensino Médio e 02 (dois) professores da escola (Anexo I). Os dados resultantes dessas entrevistas foram analisados à luz da Análise de Conteúdo (BARDIN, 2012).

O que nos interessou nesta pesquisa é exatamente que, a partir dos sujeitos entrevistados, seja possível analisar a essência do que dizem e como dizem, percebendo, desse modo, nas falas: (i) a conquista do Ensino Médio no Assentamento Palmares II; (ii) a institucionalização do Ensino Médio, em 2014; e (iii) o processo de integração/fragmentação entre os saberes sociais e conhecimentos escolares na formação dessa juventude.

Isto quer dizer que, ao entrevistar alunos, coordenação e professores, identificamos pontos de referência de como o objeto poderia ser tratado. Buscamos o envolvimento com o contexto da pesquisa, com os sujeitos que vão revelando pistas sobre o fenômeno da pesquisa, que não se restringe ao contexto escolar, mas, envolve o social, o político e o econômico.

Num segundo momento, tratamos e apresentamos as análises das respostas que obtivemos ao indagarmos acerca da importância da escola e do Ensino Médio na vida dos estudantes, buscando analisar as coerências/incoerências entre o Ensino Médio no assentamento Palmares II e os interesses da classe trabalhadora.

É nesse sentido que realizamos a pesquisa, seguindo a perspectiva do materialismo histórico-dialético, à luz do entendimento de que a ciência e o processo científico não são imunes aos embates reais que se dão na sociedade de classe, e, ainda, o que nos afirma Bachelard (1996, p. 8) sobre ser preciso, para confirmar 
cientificamente a verdade, confrontá-la com vários e diferentes pontos de vista. Além disso, quando o conhecimento expõe a historicidade do real, nas determinações que o constituem nos seus diferentes âmbitos - social, econômico, político, cultural etc., este conhecimento, como indicou Marx, se transforma em força material revolucionária.

Baseado em Marx, Engels, Gramsci e Lenin, Bachelard (1996, p. 111) considera:

O conhecimento que se constitui em força material gesta-se na práxis revolucionária; portanto não é o da ciência positivista e funcionalista que alimenta a reprodução do capital. Revolucionário é o conhecimento que se constrói dentro da concepção materialista histórica da realidade humana e do método dialético materialista histórico, que busca sua compreensão.

Compreendemos que a pesquisa sobre o Ensino Médio para os jovens assentados, a partir da educação escolar desenvolvida pela organização do MST, possibilita a reflexão acerca de uma realidade que envolve hoje uma parcela da juventude amazônica, que faz parte do movimento social que mantém esses jovens como fruto da organização iniciada no Assentamento Palmares II, por volta de 1996.

Desse modo, apresentamos as reflexões sobre a Escola Crescendo na Prática e a institucionalização do Ensino Médio com o objetivo de problematizar este estudo e o que nos levou a pesquisar tal espaço. Primeiramente, consideramos importante destacar a história da formação do MST no Brasil e no Pará, para compreender o processo dialético que resultou em vários pontos de referência para que se tornasse um dos maiores movimentos sociais da América Latina.

Tomamos o estudo de caso qualitativo, pois a pesquisa se baseia na construção do conhecimento, de forma a considerar a realidade e sua compreensão em várias dimensões. Entretanto, para o entendimento do percurso histórico da Escola Crescendo na Prática, foi necessário compreender a maneira como se constitui o movimento popular - MST - e os elementos que protagonizam sua fundação.

No tratamento dos dados, utilizamos a Análise de Conteúdo, em que foi possível compreender e afirmar a constituição de duas problemáticas. A primeira que se relaciona à implementação do currículo proposto pela Secretária de Estado de Educação do Pará (SEDUC/PA), o qual supomos que fragiliza a socialização dos saberes constituídos na vivência do movimento e das relações do assentamento. $E$ 
uma segunda relacionada ao entendimento de como de fato se constituí o Ensino Médio no contexto do Assentamento Palmares II.

\section{Considerações sobre o movimento social}

Os movimentos sociais da classe trabalhadora em nossa sociedade expressam a eloquência de vozes de muitos trabalhadores e trabalhadoras que precisam ser ouvidos, precisam ser respeitados ou, pelo menos, precisam ser lembrados diante da desigualdade social.

O Movimento Sem Terra é datado de 1984, no contexto de luta contra a política agropecuária que se instalou durante o regime militar (1964-1985), na qual era praticamente impossível qualquer nível de organização popular, sindical ou política, o que pressupõe entendermos o molde capitalista da época, baseado no desenvolvimento industrial.

Um elemento a ser considerado na constituição do movimento diz respeito aos seus constructos para com a juventude, pois é um movimento que busca meios para garantir que os jovens permaneçam no assentamento, uma vez que muitos acabam saindo em busca das seduções do capital, sendo este um dos motivos pelos quais o MST procura promover a formação política de toda família.

Segundo Caldart (2007) o MST é fruto de uma questão agrária estrutural e histórica no Brasil, que nasce, especificamente, no centro-sul do país, com o primeiro Encontro Nacional de Trabalhadores Sem Terra, realizado de 21 a 24 de janeiro de 1984, em Cascavel, no Paraná. Outro ponto a ser destacado diz respeito ao cenário de migração de um grande quantitativo da população do campo para as cidades, por causa da industrialização do campo, da substituição do homem pela máquina. A falta de trabalho para esses sujeitos oportunizou a resistência e a inquietação dos colonos, o que gerou a busca por alternativas de luta pela terra nas regiões onde viviam.

Nesse contexto, a implantação de uma agricultura baseada nas práticas capitalistas expulsou do meio rural, de forma muito rápida, grandes números de pessoas, famílias inteiras "que viviam como arrendatários, meeiros, posseiros, parceiros e até mesmo pequenos agricultores que, por fatores diversos, haviam perdido suas terras" (LAUREANO, 2007, p. 37-38). Esses fatores ocasionaram: 
[...] o aguçamento das lutas e conflitos no campo, e na luta por terra. Coube aos trabalhadores unirem suas forças e demonstrarem capacidade de mobilização e conquista de posições com a organização de "42 acampamentos até o final de 1985, com mais de 11.500 famílias sem-terra, espalhadas por vários estados do país" (GRZYBOWSKI, 1991 apud LAUREANO, 2007, p. 75).

São esses sujeitos expulsos de suas terras, explorados e perseguidos que compuseram o MST. O primeiro registro de organização massiva dos trabalhadores é datado do dia 07 de setembro de 1979, na cidade de Ronda Alta, no Rio Grande do Sul, na terra da gleba Macali. Havia mais de 1.700 famílias sem trabalho, pois tinham sido expulsos das terras dos índios Kaingang. Desse modo, essas famílias buscaram novas terras para poderem trabalhar, e acabaram aceitando a proposta do governo federal, deslocando-se para as regiões Centro-Oeste e Norte, nas conhecidas "novas fronteiras agrícolas" (LAUREANO, 2007, p. 82).

A década de 1970 foi marcada por fortes movimentos e, após a ditadura, a população brasileira continua seu processo de reorganização popular. A Central Única dos Trabalhadores (CUT), por exemplo, nasce nesse contexto, em 1983, em São Bernardo do Campo. O MST também começa a sua História com base em movimentos populares anteriores, como o das Ligas Camponesas, em 1946, Movimentos de Agricultores Sem Terra (MASTER) de 1960 a 1964, e União dos Lavradores e Trabalhadores Agrícolas (ULTAB), de 1964 (MORENO, 2011, p. 54).

Outro ponto a ser considerado é que, em meio a esse processo de industrialização do campo, o camponês é "espremido pelo latifúndio; e na cidade é forçado a viver nas favelas, talvez pior que as senzalas" (MORENO, 2011, p. 41) e, com isso, o camponês descobre que, "se ficar, o latifúndio come; e se correr para a cidade o empresário pega" (MORENO, 2011, p. 41). A saída, certamente, é ficar e enfrentar o sistema capitalista. Com isso, o MST

[...] é um movimento que representa a luta de agricultores acostumados com o trabalho familiar e que resolveram lutar pela terra. Pessoas que descobriram na luta e aprenderam a creditar, e assim passam a defender, que terra é de quem nela trabalha. Lutam contra o monopólio da terra em mãos de poucos os latifundiários. Para o MST, o latifúndio representa toda forma de exclusão: política, social e econômica da maioria da população (LAUREANO, 2007, p. 83). 
É válido destacar que, além da questão socioeconômica, houve também o aspecto ideológico com a presença da Igreja CATÓLICA, com o trabalho pastoral, e da Igreja luterana, significativo desde a gênese do MST.

A presença da Igreja foi mais forte nos estados do Paraná e Santa Catarina e essa presença ecumênica deu unidade/organicidade ao movimento, evitando sua fragmentação. A Comissão Pastoral da Terra (CPT), que surgiu em 1975, em Goiânia, foi de suma importância para a reorganização das lutas dos trabalhadores rurais, pois passou a conscientizá-los na busca de uma organização homogênea entre eles, uma forma de unir os interesses e politizar os trabalhadores (LAUREANO, 2007).

De acordo com Stédile e Fernandes (1999, p. 16, 19-20, 23) há três aspectos decisivos para compreendermos o surgimento do MST na luta pela reforma agrária no Brasil: 1) o aspecto socioeconômico: em que houve a mecanização da lavoura na região Sul do país, desencadeada pela introdução da soja, em 1970, ocorrendo o movimento de migração para o Pará, Rondônia e Mato Grosso; 2) o aspecto ideológico: a colaboração dos padres, pastores, agentes pastorais, com o trabalho pastoral, principalmente da Igreja Católica e da Igreja Luterana, imprescindível para a organização dos camponeses, sendo discutida a necessidade de organizarem-se; 3) o aspecto político: momento de luta pela democratização do país, onde a reivindicação pela reforma agrária se somou ao ressurgimento das greves operárias, em 1978 e 1979, à luta pela democratização da sociedade brasileira e contra a ditadura militar, criando as condições necessárias para o surgimento do MST.

Desse modo, o movimento tem, em suas raízes, resistir ao capital de modo que não seja submisso aos comandos e controles da política externa ao movimento, mas, que busque meios de garantir a sua "sobrevivência" no sistema. Trata-se de uma luta não apenas de direito pela terra, mas também por boas condições de produção e comercialização que exprimem a sua inserção na divisão do trabalho.

Na prática, os objetivos do MST vêm sendo desdobrados numa multiplicidade de ações coletivas, que seguem desde as reivindicações por conquistas imediatas, a luta por seus direitos de cidadania e transformação sócio-político-culturais, com ações incisivas de luta na promoção de acampamentos e nas ocupações, como 
resultado de um esforço enorme de organização coletiva fundamentada em princípios marxista-leninistas ${ }^{4}$.

Para o MST, o estudo é condição para o desenvolvimento da organização do movimento, uma forma de assumir o trabalho, de superar as dificuldades e o isolamento do meio rural brasileiro. Isso envolve a tarefa de árdua luta contra o "latifúndio do saber: discurso que circula entre os sem-terra" (CAMPOS, 2003, p. $51)$.

Com isso, é possível atribuirmos que o movimento social é fruto de uma reação contra as forças opressoras que buscam paralisar o movimento social de alguma forma para que a identidade e o seu poder de "voz" se perca. Na verdade, o movimento é o resultado de um processo em permanente construção, contribuindo para a cultura e a história do nosso povo. O MST celebra as lutas em sua caminhada, de forma a não esquecer os que tombaram lutando, de maneira que as novas gerações possam aprender com as experiências já vividas, e, nesse contexto, a educação contribui para a formação desse sujeito, uma vez que estabelece influência na vida de crianças, jovens e adultos nos próprios assentamentos.

\section{Escola Municipal de Ensino Fundamental Crescendo na Prática}

A escola que conhecemos e pela qual passamos nesta pesquisa resulta de um processo de luta travada no ano de 1996, em que a classe trabalhadora do MST se preocupou tanto com a conquista das terras da fazenda Ingá, em Parauapebas, no sul do Pará, como também para instaurar um projeto de educação que correspondesse aos interesses genuínos do movimento.

Compreendemos que a educação do MST é uma necessidade, não apenas para obter conhecimento, mas, também, uma necessidade fundamental para resolver os problemas da luta política (STÉLIDE; FERNANDES, 1999, p. 18). Entender a escola para o MST é ultrapassar as dimensões simplistas estabelecidas pela sociedade do "saber".

\footnotetext{
${ }^{4} \mathrm{O}$ primeiro criou teorias que revolucionaram a concepção de mundo, e advogou a necessidade de os trabalhadores se organizarem de forma independente e tomarem o poder de Estado, para construir um novo modo de produção, o comunismo. O segundo, líder revolucionário russo, desenvolveu o marxismo aplicado à realidade de seu país e foi um dos principais dirigentes da Revolução Russa (MORENO, 2011).
} 
Tomamos a Escola Crescendo na Prática como caso a ser estudado. A escola fica situada no assentamento Palmares II, no sudeste do Pará, a $20 \mathrm{~km}$ de Parauapebas, tendo uma área de $6.886,208 \mathrm{~km}^{2}$. Segundo os dados do IBGE Instituto Brasileiro de Geografia e Estatística (2019), Parauapebas possuía 153.908 habitantes, sendo 15.218 pertencentes à zona rural (7.839 homens e 7.379 mulheres) e 138.690 da zona urbana. Dessa população, 52.707 são alfabetizados. Entre 15 e 29 anos, 37.162, representa o número de alfabetizados.

Durante os anos 1960, a região foi palco do grande "formigueiro humano", resultado da ocupação de terras da região de Serra Pelada e adjacentes. Anos depois, o governo federal concedeu à Companhia Vale, à época estatal, o direito de explorar o minério. Parauapebas se situa em uma região da Amazônia rica em minérios e a economia do município é baseada na extração mineral (ferro, ouro e manganês), sendo que, na década de 60 , foi descoberta a maior reserva mineral do mundo em Carajás, no então município de Marabá (IBGE, 2019).

$\mathrm{O}$ assentamento Palmares ${ }^{5}{ }^{5}$, onde está situada a Escola Crescendo na Prática, lócus desta pesquisa, possui uma área de 16.111 hectares, com aproximadamente 2.000 famílias assentadas, fruto de uma ocupação ocorrida em meados de 1990, na fazenda Ingá.

O Quadro 1 registra o crescimento demográfico da cidade de Parauapebas, de 1991 a 2015, sendo possível observar que a ocupação6 ${ }^{6}$ da região se deu de forma acelerada, em especial, no ano de 1996. Em seguida, é possível localizar no Mapa 10 assentamento Palmares II, fruto das organizações trazidas pelo MST para a região.

\footnotetext{
${ }^{5}$ Dados do INCRA - Instituto Nacional de Colonização e Reforma Agrária (2000) revelam que o número de assentamentos pertencentes a área Pará/Marabá chega a 505, com número de 71.868 famílias assentadas e área de total 4.641.357,16 (ha). O número de assentamento com mais de 10 anos chega a 434 assentamentos, com 64.486 famílias, e com relação a assentamentos com menos de 10 anos, são 71 , tendo 7.382 famílias.

${ }^{6}$ Essa ocupação se deu com base em projetos do governo federal, por meio do Incra: a "febre" do ouro em Serra Pelada; os empregos gerados pelos grandes projetos, como Grande Carajás, e pela Companhia Vale do Rio Doce, que, em conjunto, trouxeram para a região trabalhadores de todo país (CAMPOS, 2003, p. 84).
} 
Quadro 1 - Crescimento demográfico de Parauapebas - 1991-2015

\begin{tabular}{|c|c|c|c|}
\hline ANO & PARAUAPEBAS & PARÁ & BRASIL \\
\hline $\mathbf{1 9 9 1}$ & 53.335 & 4.950 .060 & 146.825 .475 \\
\hline $\mathbf{1 9 9 6}$ & 73.831 & 5.466 .141 & 156.032 .944 \\
\hline $\mathbf{2 0 0 0}$ & $\mathbf{7 1 . 5 6 8}$ & $\mathbf{6 . 1 9 2 . 3 0 7}$ & $\mathbf{1 6 9 . 7 9 9 . 1 7 0}$ \\
\hline $\mathbf{2 0 0 7}$ & 133.298 & 7.065 .573 & 183.987 .291 \\
\hline $\mathbf{2 0 1 0}$ & $\mathbf{1 5 3 . 9 0 8}$ & $\mathbf{7 . 5 8 1 . 0 5 1}$ & $\mathbf{1 9 0 . 7 5 5 . 7 9 9}$ \\
\hline $\mathbf{2 0 1 5}$ & $\mathbf{1 8 9 . 9 2 1}$ & $\mathbf{8 . 1 7 5 . 1 1 3}$ & $\mathbf{2 0 4 . 4 5 0 . 6 4 9}$ \\
\hline
\end{tabular}

Fonte: elaborado pela autora com dados do Censo Demográfico 1991, Contagem populacional 1996, Censo Demográfico populacional 2007 e Censo Demográfico 2015 do IBGE.

Mapa 1 - Localização do assentamento Palmares II (Sul)

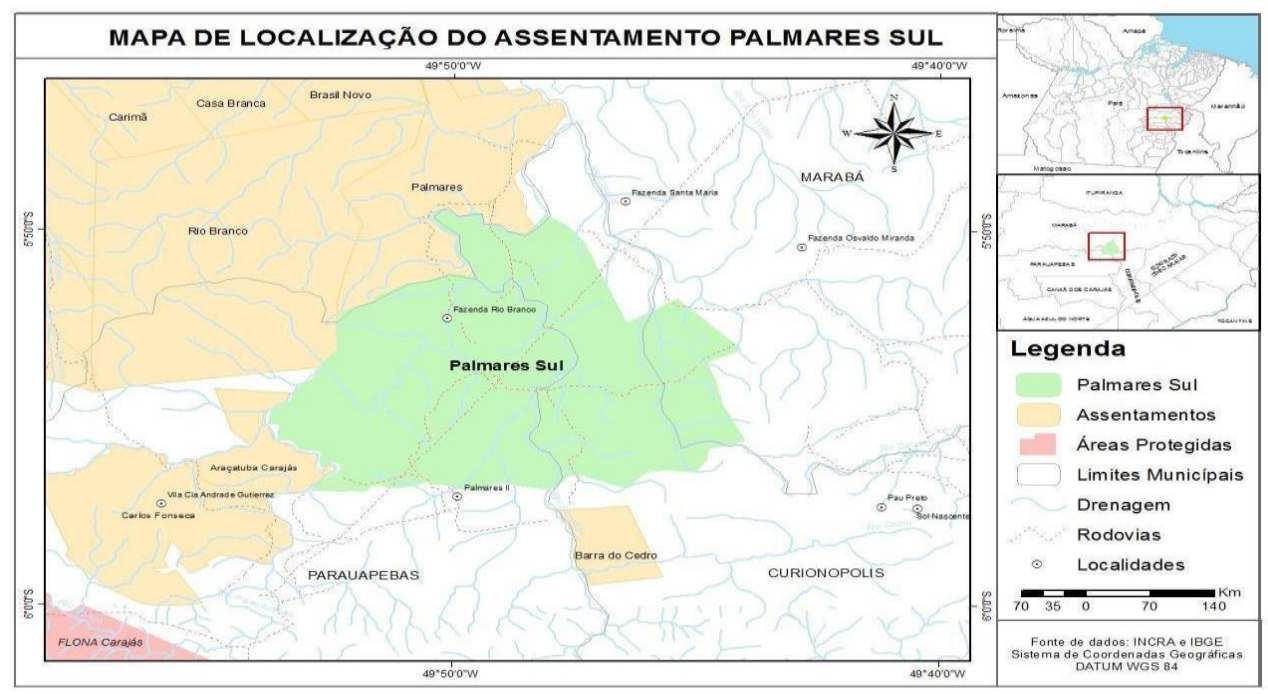

Fonte: elaborado pela autora com dados do INCRA e IBGE.

Segundo Campos (2003) quando o MST chegou ao Pará, em 1989, a ocupação de terras e seus conflitos se dava por meio do Sindicato dos Trabalhadores Rurais (STR), ligado à Federação dos Trabalhadores da Agricultura (FETAGRI) ou mesmo pelas mãos da liderança responsável pelas invasões.

É válido ressaltar que, primeiramente, no estado do Pará, quanto à imigração de um grupo de assentados que saiu de Conceição do Araguaia para ocupar as terras onde hoje se encontra Palmares, a ocupação deriva do contexto social que transcorria na época, da famosa "Serra do Carajás", espaço de grande exploração de ouro na região sul do Pará. Nesse período, várias pessoas migraram para essa região na busca de "melhores condições" de vida (relato do Coordenador cedido em 2015).

A Escola Crescendo na Prática nasce exatamente em 1996, como atestam as falas das entrevistas colhidas na pesquisa de Campos (2003) com os alunos e professores, no qual percebemos o sentimento de pertença e de conquista, 
conforme podem ser percebido nos trechos de A, B, C e D (sujeitos identificados da pesquisa de campo), quando dizem:

Essa escola foi uma conquista nossa, né? (A).

A gente foi pra frente da prefeitura, todo mundo, né? Os alunos, os professores, nossos pais, né? Aí gente ficou acampado lá até a prefeitura receber a gente e acertar que ia fazer nossa escola (B). Pra conquistar essa escola aqui foi uma luta danada... a gente passou muito tempo lutando, brigando, teve até greve de fome lá na prefeitura uma vez pra poder a prefeita receber a gente (C).

Não foi ninguém não que trouxe essa escola pra cá, não, fomos nós que construímos essa escola aqui, com a nossa luta, os professores, nossos pais, a gente foi várias vezes em caminhada até lá em Parauapebas pra poder ter essa escola aqui, né? (CAMPOS, 2003, p. 107).

Como podemos perceber nas falas, a escola é fruto da luta de pais, professores, alunos, que, durante os anos de 1990, colocaram-se em marcha para ocupar a sede da Prefeitura de Parauapebas em busca da implantação da Escola Crescendo na Prática. Ou seja, a escola foi constituída após árduo trabalho pelos militantes e corresponde aos interesses por educação escolar de qualidade que atendesse aos filhos do grupo de trabalhadores oriundos do MST.

No momento da entrevista, o número de estudantes era de 1.332, incluindo o ensino regular, educação infantil, Ensino Fundamental e Médio, sendo 460 alunos do Ensino Médio e na modalidade EJA; deste número, 20 alunos são pertencentes ao 3ํano do Ensino Médio, sujeitos de nossa pesquisa.

Por sua vez, a preocupação da escola está presente desde o início da construção do assentamento, em seus primeiros acampamentos: a necessidade do acesso à escola por parte dos jovens/crianças para que fossem alfabetizados.

Segundo Dalmagro (2011) para o MST, a escola é vista como um espaço onde crianças e adolescentes estão se formando como seres humanos integralmente. Isso implica dizer que não é apenas um lugar para a aprendizagem teórica, porém, é o lugar do saber, do estudo e trabalho.

Todavia, o acesso ao elaborado conhecimento escolar não deve ser visto como um fim em si mesmo, mas, uma relação de integração com a realidade e da sua transformação. Justifica aqui a práxis, enquanto articulação entre teoria e prática, "na qual o envolver do homem com a realidade vai produzindo saberes que se emolduram à medida que se vão gestando no cotidiano dos sujeitos" (RODRIGUES; ARAUJO, 2014, p. 170). Acrescentamos a anuência da perspectiva 
adotada pelos autores na dimensão em que o saber social e o conhecimento tomem sua importância para que a formação integral assumida pelo MST se efetive no cotidiano escolar das instituições assumidas pelo movimento.

\section{A escolarização no Ensino Médio: a história de conquista, luta e resistência}

Diante da grande fragilidade do acesso à educação pública de qualidade por parte dos filhos da classe trabalhadora do Assentamento Palmares II, a fase de institucionalização do Ensino Médio modular ganha força em 2005, sendo fatores responsáveis por essa situação, primeiramente: a) a necessidade social; b) a necessidade da comunidade estudantil; e c) materialização do direito ao ensino.

A necessidade social pauta-se na bandeira de luta do próprio movimento, de garantir educação para a juventude do assentamento, uma vez que os jovens tinham que sair de sua localidade e ir até a cidade de Parauapebas para poderem continuar os estudos.

Além disso, os pais, jovens, representantes do movimento, acreditavam que garantir o Ensino Médio regular dentro do assentamento assegurava a constituição de uma educação pautada nos princípios do movimento social, em que confirmam não só o acesso à escrita e à leitura da palavra, mas, a compreensão de mundo necessária para se constituírem como cidadãos, como sujeitos de direitos, pois o MST considera a educação uma ferramenta de luta política e aprofundamento do conhecimento, por assim dizer, entre os "intelectuais orgânicos da classe trabalhadora" e as "organizações de trabalhadores do campo e da cidade" (GRAMSCI, 1991, p.119).

Segundo os dados do Instituto Nacional de Estudos e Pesquisas Educacionais Anísio Teixeira (INEP) no ano de 2014, o número de escolas em área de assentamento registra 4.225 escolas, sendo que o Pará lidera, com 1.042 (mil e quarenta e duas) escolas em área de assentamento, sendo 159 (cento e cinquenta e nove) escolas de Ensino Médio. Trata-se, pois, de uma configuração escolar que se manifesta nas engrenagens do movimento, seja por influência do MST ou sob sua coordenação, a qual configura o desenvolvimento do conhecimento escolar em consonância com os preceitos do movimento para a formação do sujeito assentado. 
Desse modo, compreendemos as dificuldades recorrentes para a constituição de políticas públicas para a universalização do Ensino Médio e, entre estas, está à definição de sua identidade, que ultrapasse o sentido de trampolim para a universidade ou a formação profissional (KRAWCZYK, 2011).

O Ensino Médio é historicamente marcado por sua indefinição de identidade: ora está para a formação dos alunos para estudos posteriores, ora para a preparação para o mundo do trabalho. Isto é, a rigor, esse nível de ensino tem sido direcionado a preparar o sujeito para o Exame Nacional do Ensino Médio (ENEM) ${ }^{7}$ e para o mundo do trabalho. Este fato resulta, principalmente, das etapas de sua institucionalização, desde a reforma educacional do Ministro Francisco Campos (Decreto o 18.890/31) até recentemente, com o parecer CNE/CEB № 07/2010 e a resolução CEB no 04/2010, que delibera sobre as Diretrizes Curriculares Nacionais Gerais para Educação Básica, e com a Reforma do Ensino Médio, pela Lei 13.415/2017, com ênfase nos novos componentes curriculares e pelos itinerários formativos.

Por outro lado, esse processo de ampliação não pode ser caracterizado enquanto universalização, nem democratização do Ensino Médio, uma vez que a porcentagem de jovens fora da escola, além dos índices de reprovação e evasão devem ser considerados (KRAWCZYK, 2011).

O Ensino Médio acentua o momento em que os jovens estão configurando seus horizontes, em termos de cidadania e de vida economicamente ativa, onde a experiência educativa deve proporcionar o desenvolvimento intelectual e a apreensão de elementos culturais que possibilitem a configuração desses horizontes.

Com isso, consideramos que a categoria contradição ajudou a compreender esse processo de escolarização do Ensino Médio que possui o MST, suas relações e contradições que possuem os saberes sociais e conhecimentos escolares na sua essência.

No caso da Escola Crescendo na Prática, no entanto, houve a necessidade de lutar também por uma forma institucionalizada de Ensino Médio regular, já que

\footnotetext{
${ }^{7}$ Não é objetivo, nesta pesquisa, realizar uma análise sobre o ENEM, mas, estreitar o entendimento do que tem sido o papel do Ensino Médio.
} 
o estado ofereceu, em 2005, apenas o ensino por meio de Módulo8. Esta configuração desmotivava os alunos, sendo este um dos motivos de base de luta para que fosse institucionalizado, como se pode perceber nas falas do coordenador e dos professores de Filosofia e Sociologia: "uma vez que faltavam professores, os alunos sentiam-se prejudicados pelo ensino fragmentado que estava sendo ofertado no ensino modular, sem contar o sentimento de exclusão, que indicaria que a institucionalização do Ensino Médio na Escola Crescendo na Prática poderia ser de qualquer forma".

Somente em 2014, após momentos de debates, ocupação e apreciações junto à SEDUC/PA, o Ensino Médio no assentamento Palmares II passou a ser regular:

O aluno terminava a oitava série, ele saia e ia estudar em Parauapebas, ai várias escolas lá, e tinha uma escola exclusiva praticamente pra receber os alunos de Palmares, né? Que é uma escola mais próxima daqui da parada de ônibus né? Então, em 2004 a gente iniciou um debate pra construção do Ensino Médio né. Então em 2005, tivemos as primeiras turmas de Ensino Médio modular, que era o que o estado podia oferecer (relato do Coordenador cedido em 2015).

Esses pontos surgem a partir do momento em que a comunidade percebe que o direito ao acesso ao ensino se encerra no Ensino Fundamental, e os alunos teriam que se deslocar para o centro da cidade para poderem concluir seus estudos, fato que concentrou inquietações e reprovações por parte da escola, comunidade e alunos.

As falas sobre o que o estado podia oferecer têm a tônica de conformação por parte da comunidade, por ser submetida às condições de educação incompatíveis com a formação humana e o empoderamento dos saberes sociais. No entanto, o Ensino Médio modular "conquistado" naquele momento não garantiu aos alunos as condições necessárias e suficientes para o desenvolvimento da relação entre os saberes sociais e conhecimento escolar, tão relevante para o processo de ensino-aprendizagem desses jovens pelo distanciamento cultural e

\footnotetext{
${ }^{8}$ As primeiras turmas do Ensino Médio no Assentamento foram ofertadas por Módulo de ensino, o que significa que cada disciplina é trabalhada de forma individual (uma por vez), por um período, e atende às exigências de sua carga horária anual. Por exemplo, o módulo de Língua Portuguesa com a carga horária de uma determinada série poderá ser concentrado num período de trinta e dois (32) dias, com seis (6) horas/aula por dia (ANDRADE, 2008).
} 
político do que era ensinado, em relação à realidade em que viviam os alunos do movimento.

Ele só vem dá aula dele normal, vem explica. (A2)

No ensino médio nunca teve, estudar sobre a questão do movimento. (A3) (relato dos alunos cedido em 2015).

Nessa situação, o que ocorre é a fragilização da própria cultura, do próprio saber social da comunidade local, pois as relações entre professor e aluno foram demasiadamente difíceis. Professores provenientes de fora do assentamento, sem práticas adequadas e com dificuldades de trato na educação dos jovens do Ensino Médio no contexto do movimento, com sérios problemas de disciplina, compromisso, respeito e reconhecimento de que a educação que estava sendo constituída naquele momento pertencia a uma área de reforma agrária.

Este fato veio sendo protelado durante dez anos, evidenciando um dos motivos pela fragmentação entre o saber social e conhecimento escolar.

E nós tínhamos muitos enfrentamentos, principalmente por preconceito por ser aluno de assentamento, de reforma agrária né. Aí o aluno se perdia, praticamente perdia a disciplina, tinha que pagar disciplina, porque o professor tinha abandonado a turma (relato do Coordenador cedido em 2015).

Um impasse perceptível na fala do coordenador a educação aqui introduzida ocorreu de "fora para dentro"; não houve diálogo com a comunidade e nem mesmo a valorização da realidade da comunidade, como se percebe na fala do Coordenador.

Assim, compreendemos que o Ensino Médio que veio sendo consolidado no contexto do assentamento Palmares II, desde 2005, no ensino modular, é também um espaço de disputa, pois o Ensino Médio fortalece a formação do sujeito para inserção na Universidade, o que não nega que esse sujeito também tenha a sua formação política, cultural, histórica valorizada nesse processo, ponto central da tese estabelecida pelo MST, de defesa da educação enquanto coração do movimento, uma educação pautada na valorização da cultura, da vivência desses sujeitos, em que se estrutura a formação política, ideológica e histórica.

A grosso modo, a institucionalização do Ensino Médio modular, mesmo sendo reconhecida, não assegurou as condições mínimas para o seu funcionamento e se manteve de maneira "irregular e precária". Embora essa tenha sido uma conquista após um longo processo de luta, as primeiras turmas foram 
concentradas em uma casa alugada pelo governo, com infraestrutura inadequada para concentrar os alunos:

Era um lugar que era uma casa de família arrendada por não sei quantos milhões pra permanecer num sei o quê, mas lá não tinha condições de ser escola lá era difícil de ensinar, eu tive muita dificuldade de ensinar, achava poeiral na escola [...], mas graças a Deus nós viemos pra cá diminuiu mais (relato do Professor 1 cedido em 2015).

\section{Foto 1 - Escola Municipal de Ensino Fundamental Crescendo na Prática, Palmares II}
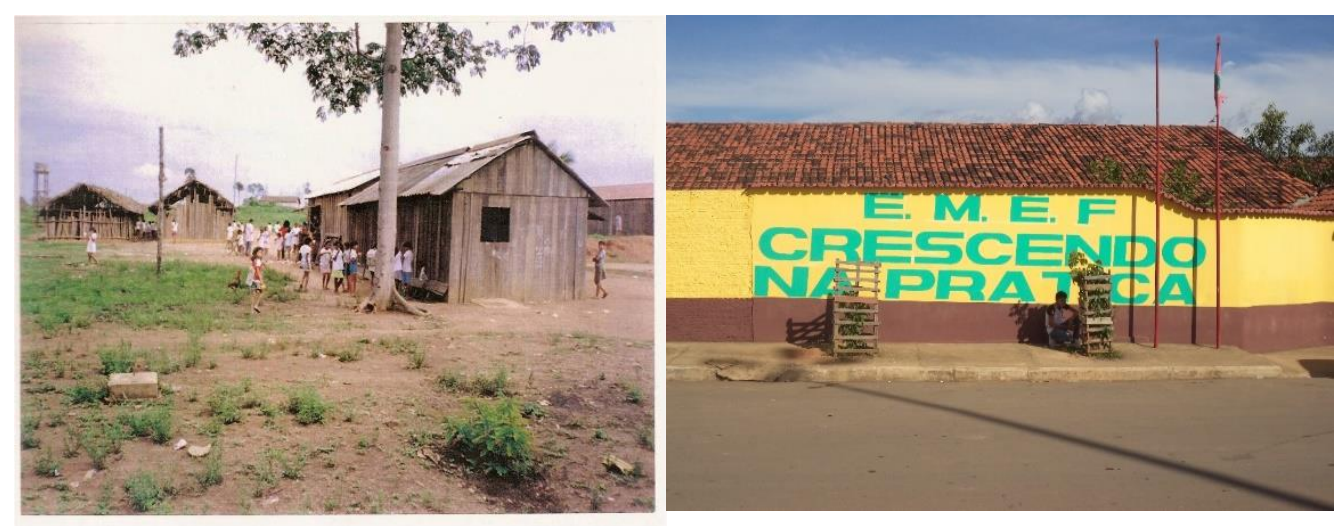

Fonte: acervo da Pesquisa de Campo, 2015.

Ou seja, as condições das primeiras turmas do Ensino Médio carregavam uma situação demasiadamente difícil, desde a sua estrutura física até a lotação de professores que geralmente não tinham vínculo efetivo de trabalho, sobretudo, do ponto de vista estrutural e da falta de compromisso por parte do corpo docente com relação à formação dos jovens.

Nesses trechos, compreendemos a situação em que as aulas do Ensino Médio ocorriam e a forma como fora tratada a inserção do modular por parte, principalmente, do poder público e dos professores. O descompromisso com a formação dos jovens se afirmou no simples exercício do cotidiano escolar e o descumprimento dos módulos foi maior que o desejo de contribuir para a unidade teórico e prática (RODRIGUES; ARAUJO, 2014).

A partir disso, ressaltamos que a conquista do Ensino Médio modular na Escola se deu, principalmente, pelo movimento constante instalado no interior do movimento social, mas, ainda assim, relacionado a uma lógica de reduzir a educação da classe trabalhadora, o que significa dizer que a educação dessa classe não tem espaço, pois não é interesse da burguesia que "[...] desfrute dos prazeres da cultura e do coletivo das letras, das artes e do espírito, seu lócus não está ai, seu 
papel será preparar a festa, produzir os alimentos, trabalhar" (ARROYO, 2002, p. 92).

Com isso, os alunos revelaram insatisfações com uma escola exageradamente teórica, alheia a muitos problemas que eles enfrentavam fora dela, que não os tomava como interlocutores possíveis e que também não lhes oferecia a estrutura material e o suporte profissional necessários para cumprir mesmo aquilo que é legal, ou seja, a educação que se tem apresentado ao Ensino Médio, muitas vezes, não corresponde ao que a Lei de Diretrizes e Bases da Educação propõe: a consolidação e o aprofundamento dos conhecimentos adquiridos no Ensino Fundamental, possibilitando a continuidade dos estudos; a preparação para o trabalho e a cidadania; o aprimoramento do educando (ético, intelectual e crítico); e a compreensão dos fundamentos científicos-tecnológicos dos processos produtivos (teoria e prática) (BRASIL, 1996).

Atualmente, a Escola possui uma boa estrutura, destacando-se que a conquista se deu, principalmente, pela luta estabelecida desde as primeiras habitações nesse território. Durante a nossa pesquisa, percebemos que a instalação da Escola trouxe alguns benefícios para o assentamento, como o prédio novo, estruturado para as atividades escolares.

Por outro lado, houve problemas que se apresentaram no decorrer da constituição do Ensino Médio, principalmente quanto ao corpo docente da escola, pois os professores não pertenciam ao assentamento, o que dificultava a relação e desenvolvimento da aprendizagem dos alunos e o próprio sentido de educação para eles, como exposto no diálogo a seguir:

“[...] pra mim o ensino médio significa... com certeza pra eu subir numa escada eu preciso me preparar mais por que depois que eu sair do ensino médio, claro, poder cursar uma faculdade". (A1)

Ele ajuda bastante, porque tem certos assuntos que a gente fica pensando é porque eu tô vendo isso não sei pra quê, mas lá na faculdade, eu acredito que essas coisas que a gente não dá tanto valor vai ajudar bastante. (A2) (relato dos alunos cedido em 2015).

Nesse aspecto, percebemos o dilema existente na escola, pois a fala mostra que houve nesse processo muitos enfrentamentos que passaram desde a formação dos professores ao preconceito existente entre os assentados. Além desse, outro ponto colocado na fala acima apresentados podem ser compreendidos a partir da ótica da escolarização desses sujeitos, que passa a ser compreendida enquanto 
"precondição para sobreviver na lógica da sociedade capitalista", e neste fato, resume-se outro ponto da fragmentação em que tem sido desenvolvido o Ensino Médio desses sujeitos da classe trabalhadora. Chegamos a inferir que a educação do Ensino Médio desenvolvida no e não do assentamento, pois, observamos por meio das análises, que o processo fragmentação latente deriva principalmente da anuência do currículo proposto pelo sistema de educação, e aí a educação não é instrumento da emancipação humana, mas mecanismo de perpetuação e reprodução desse sistema (MÉSZÁROS,2008, p. 15).

De certa forma, o modo como o Ensino Médio regular foi desenvolvido se refletiu no estabelecimento do movimento descompromissado com a formação humana desses alunos, que, de certa, rompeu com um dos princípios estabelecidos pelo próprio movimento, que envolve a questão do corpo docente pertencer ao assentamento, justamente para garantir $\mathrm{o}$ fortalecimento da identidade $\mathrm{e}$ emancipação do saber social.

Sobre este aspecto, a Resolução no 23/2007 do CNE/CEB (BRASIL, 2007) estabelece que a escola do assentamento deve ter:

- professores simpatizantes da reforma agrária;

- conteúdos incluindo a história do MST;

- livros contendo a experiência dos sem-terra;

- e relação professor-aluno como uma relação de companheirismo.

No que tange à Resolução ํo 02/2008, é destacada em seu art. $1^{\circ}$ a concepção da escola de assentamento:

A Educação do Campo compreende a Educação Básica em Educação Infantil, Ensino Fundamental, Ensino Médio e Educação Profissional Técnica de nível médio integrada com o Ensino Médio e destina-se ao atendimento às populações rurais em suas mais variadas formas de produção da vida - agricultores familiares, extrativistas, pescadores artesanais, ribeirinhos, assentamentos e acampados da Reforma Agrária, quilombolas, caiçaras, indígenas e outros (BRASIL, 2008, p. 1).

Com isso, identifica-se que a educação no assentamento deva atribuir interesses diferenciados ao que nos revela os depoimentos sobre a luta que veio sendo travada, desde 1996, para conseguir o Ensino Médio na Escola Crescendo na Prática. 
Trata-se de uma luta fundamental, quando tratamos da educação da classe trabalhadora. As lutas são constantes e o desafio para se ter o pouco acesso a este nível de ensino é marcado por uma lógica homogeneizadora de pouca educação e muita escolarização para os sujeitos que fazem parte desse processo de construção do conhecimento científico.

O que podemos perceber nas análises sobre a educação do Ensino Médio desta escola, destinada a atender aos interesses da classe trabalhadora, não leva em conta os meandros da constituição histórica exercida pelo Movimento Social frente ao processo de luta contra os interesses contrários à educação do trabalhador. Pelo contrário, observamos que as relações estão embasadas em conhecimentos conteudistas que se limitam a compreender a realidade existente, visto que muitos desses jovens trazem o saber social (saber sobre a política do movimento, saber popular, saber social) e que poderiam ser aproveitados nas práticas educativas; assim, estas se mostram fragmentadas na formação.

Semeraro (2006) baseado em Gramsci, analisa o conhecimento a partir dos interesses da classe trabalhadora, que inspira as classes populares a passar por um processo constitutivo de sua identidade, de sua intelectualidade e por uma educação que exija a construção rigorosa de um saber mais avançado e socializado.

É precisamente neste âmbito que está a reflexão e o desafio ao Ensino Médio desenvolvido aos jovens da classe trabalho no assentamento Palmares II. A escola é lócus de dominação e, portanto, de conflito, de resistência. É fruto de intenso processo de reivindicação pelos direitos sociais: primeiro, à posse de terra e, posteriormente, à educação. É marcado por intenso repasse dos valores do Movimento dos trabalhadores Sem Terra e daqueles que iniciaram a ocupação que resultou no assentamento Palmares II. Para tanto, é imprescindível analisar profundamente as relações.

Para Arroyo (2012) os jovens e adultos que chegam ao Ensino Médio carregam em si uma experiência de luta pela escola, pelo conhecimento, experiências de tensas relações entre trabalho-sobrevivência-estudo. Isso decorre, principalmente, da realidade que se nos apresenta, de que nem todos têm lugar na escola, que é restrita, sendo os filhos de trabalhadores os menos favorecidos, uma 
vez que a "educação tornou-se um instrumento da sociedade capitalista, vista, grosso modo, como mercadoria, como espaço de disputa" (ARROYO, 2012, p. 16).

Nesse contexto, pouca interligação há com os saberes sociais, práticas sociais dos sujeitos que fazem parte desse processo de formação; e a educação ganha sentido enquanto fator de desenvolvimento, situação que a reduz para formação de recursos humanos, formadora de capital humano, "onde as questões educacionais se reduzem a uma contabilidade, em última análise, de custo/benefício" (GRZYBOWSKI, 1991, p. 49). Além disso, há a necessidade de criar o coletivo pedagógico e a formação permanente dos educadores e educadoras, onde é possível constituir uma equipe ou núcleo de educação com objetivo de discutir sobre as práticas de educação do acampamento focando em torná-las cada vez mais orgânicas.

Ou seja, a prática escolar que alguns professores exerciam/exercem no Ensino Médio rompia com os princípios do próprio movimento. No entanto, esses constantes problemas e enfrentamentos desencadearam em 2009 uma paralização pelos alunos do Ensino Médio na Escola Crescendo na Prática.

Outro ponto a ser destacado é que essa institucionalização não permitiu que os princípios do MST mantivessem espaço junto ao conhecimento escolar; nem mesmo o próprio Projeto Político Pedagógico (PPP) da escola do Ensino Médio, no momento da entrevista, encontrava-se em construção. "Então nós agora estamos criando o PPP da escola, organizando a proposta pedagógica né? Tentando incorporar nós enquanto escola mesmo" (relato do Coordenador cedido em 2015), fato este que revela a frágil posição dos interesses da classe trabalhadora.

O movimento lutou pelo Ensino Médio no âmbito do assentamento Palmares II, no entanto, a formação que foi estabelecida desde 2005 fragmentou a formação desses jovens, uma vez que os professores não eram do assentamento e essa relação já dificultava pela implementação do currículo oficial, pois um dos princípios da educação do assentamento é que os professores façam parte do assentamento e entendam enquanto prática de ensino a importância do mesmo, ou seja, a relação com o saber social desses jovens em sua dimensão dialética estava fragmentada, distanciando a materialização da integração do saber-fazer. 
É com esse movimento fragmentado que o Ensino Médio vem se constituindo na escola que foi conquistada pelo MST e que, por outro lado, vem perdendo sua identidade.

Os objetivos que estes percorrem para a manutenção dessa "nova" conquista, o Ensino Médio regular, veio estabelecendo novas metas, novos planos, ainda "cru", em construção no momento da entrevista, diante de tantos desafios que passariam a ser conduzidos por eles, uma vez que nem todos os moradores do assentamento mantêm aproximação com o movimento, e, muitas vezes, não aceitam a participação dos jovens nessas atividades, fato que percebemos ser um entrave para que a proposta do MST, de uma formação atrelada ao movimento, ocorra de fato.

Desse modo, ao analisarmos os conteúdos das falas, chegamos a inferir que esta educação que se assume no Ensino Médio tem sentido de instrumento para atingir os espaços da universidade ou do mercado de trabalho. Podemos extrair que a instituição escolar dentro do assentamento Palmares II tem o tom de escola convencional, na qual o discurso de formação para o mercado de trabalho faz parte. Não estamos aqui suprimindo a importância da formação que tem sido instituída na escola, ainda que somente no campo do discurso, porém é necessário avançar nas análises e compreendermos que a escola no assentamento é resultado das lutas que se estabelecem para a efetivação da garantia de direitos e, ainda ao que se infere, há necessidade de continuar a "peleja" por um processo de ensinoaprendizagem que esteja pautada na formação humana integral. Como sucede o princípio da educação regida por este movimento, o MST.

\section{Algumas considerações}

No decorrer do artigo, destacamos alguns pontos de maiores tensões e disputas no que consiste à institucionalização do Ensino Médio no Assentamento Palmares II, pois essa disputa não foi suficiente para garantir que os princípios do MST mantivessem espaço junto ao conhecimento escolar, nem mesmo no próprio PPP da escola do Ensino Médio, que, no momento da pesquisa, encontrava-se em construção. O movimento lutou pelo Ensino Médio no âmbito do assentamento 
Palmares II, no entanto, a relação que foi sendo estabelecida desde 2005 fragmentou a formação de identidade da juventude do assentamento.

A escola, especialmente, o Ensino Médio, exercia função fragmentada, visto que não havia relacionamento entre o cotidiano do assentamento e o conhecimento escolar, disperso no sistema disciplinar implementado pela SEDUC/PA para a escola analisada neste estudo.

Fato interessante é que, segundo os relatos, a valorização do entorno e seu histórico de lutas estão presentes nas atividades do Ensino Fundamental; isso se deve ao fato de o MST manter maior ingerência sobre o cotidiano escolar, bem como sobre a manutenção dos professores pertencentes ao próprio assentamento no corpo docente da escola.

Sobre o objetivo de discutir o processo de escolarização no Ensino Médio de jovens filhos dos trabalhadores pertencentes ao assentamento Palmares II na Amazônia paraense, notamos que a escola, por meio do Ensino Médio, é difusora de um conhecimento não articulado com a história, com a luta e com a vida da comunidade à qual pertence. Fato ilustrativo é a atuação dos professores que vinham de fora do assentamento, davam suas aulas e iam embora sem dialogar com a complexidade de conhecimentos que ajudaram a formar Palmares II. Assim, o currículo efetivado na escola primava por um saber disciplinar, que enclausurava os conteúdos e não os permitia transitar por aquele espaço, fruto de uma conquista no embate entre classes.

Consideramos ainda que a conquista do Ensino Médio não significa que exista um ensino que seja integralmente segundo os anseios e desejos do movimento. Caso a luta não seja permanente, abre-se espaço para disseminar a negação da própria identidade do movimento no assentamento, de maneira que uma conquista acaba por fragilizar o movimento.

A relação de saberes sociais e conhecimentos escolares dentro desse discurso e a formação da identidade da juventude da classe trabalhadora precisam superar a visão de que a educação se reduz à mera necessidade escolar, mas, assume uma importância em si mesma como elemento que ajuda a fortalecer o próprio MST, quando há essa valorização do saber social, produzido socialmente, concentrando o objetivo de fortalecer o movimento por meio do trabalho, da história, das relações sociais, ou seja, na sua dimensão histórica, filosófica e política, junto 
à escola, integrado aos conhecimentos escolares (o conteúdo, a prática pedagógica etc.), havendo assim perspectiva de superar o modelo hegemônico de educação e fortalecer a ocupação do campo do saber, registrando-se a luta de classes.

É de suma importância que o corpo docente seja parte integrante desse processo, que se identifique com o movimento, que assuma seu posicionamento político, no sentido de garantir a construção do conhecimento nas dimensões política, social, crítica, reflexiva e transformadora; que venha, em especial, fortalecer o movimento e não, de alguma forma, fragmentar o que vem sendo expresso desde o Ensino Fundamental e nas formações do próprio MST.

Sobre este ponto, cabe inferir que o Ensino Fundamental vem atribuindo o sentido integrado entre saber social e conhecimento escolar e, quando passamos ao Ensino Médio, ocorre a fragmentação, porque, este corpo docente, muitas vezes, não assume o mesmo caráter que os professores do Ensino Fundamental, o que prejudica a relação entre o saber e o conhecimento.

A escola frequentemente tem sido utilizada como espaço de reuniões, de cursos, de projetos, porém, a própria educação do Ensino Médio não está sendo incluída nesse processo. No entanto, permanecem em questão as formas como acontece o processo de ensino-aprendizagem nessa sociedade (o assentamento do MST). Como afirmou o Coordenador do Ensino Médio, as ideias eloquentes de apropriação das terras levariam à desarticulação entre povo e Estado, o que resultaria, mais tarde, na constituição do Ensino Médio modular, em 2005.

Os alunos, em princípio, continuam com seus saberes fragmentados dentro do próprio lócus que foi resultado da luta dos trabalhadores. Só a conquista do Ensino Médio não garantiu a associação entre o saber local e o conhecimento constituídos nos programas e currículos para esse grau de ensino e, assim, acaba por negar o saber social desses jovens e afirmar conhecimentos fragmentados da realidade social que os cerca.

E é aí que tem de haver, na verdade, a progressiva conquista dos trabalhadores no domínio sobre seus interesses enquanto classe social, para o que é necessário intensificar uma efetiva posição política/ideológica, a fim de garantir, realmente, a formação omnilateral que o próprio princípio filosófico e pedagógico do MST almeja. 


\section{Referências}

ANDRADE, M. F. R. Uma sala de aula na proposta de ensino modular: o ensino de Português. [S.I.:S.n.,2008]. Disponível em: https://educere.bruc.com.br/arquivo/pdf2008/183 131.pdf. Acesso em: 17 jun. 2020.

ARROYO, M. O direito do trabalhador à educação. In: MINAYO, C. et al. Trabalho e conhecimento: dilemas na educação do trabalhador. São Paulo: Cortez, 2002. p. 75-92.

ARROYO, M. Outros sujeitos, outras pedagogias. Petrópolis: Vozes, 2012.

BACHELARD, G. A formação do espírito científico: contribuição para uma psicanálise do conhecimento. Rio de Janeiro: Contraponto, 1996.

BARDIN, Laurence. Análise de conteúdo. Trad. Luís Antero Reto, Augusto Pinheiro. São Paulo: Edições 70, 2012.

BRASIL. Conselho Nacional de Educação. Câmara de Educação Básica. Resolução CNE/CEB № 23, de 12 de setembro de 2007. Diretrizes Operacionais para a Educação Básica nas Escolas do campo. Brasília, DF, 2007.

BRASIL. Conselho Nacional de Educação. Câmara de Educação Básica. Resolução CNE/CEB № 2, de 28 de abril de 2008. Diretrizes Complementares para o atendimento da Educação Básica do Campo. Brasília, DF, 2008.

BRASIL. Lei no 9.394, de 20 de dezembro de 1996. Estabelece as diretrizes e bases da educação nacional. Brasília, DF, 1996. Disponível em: http://www.planalto.gov.br/ccivil 03/leis/19394.htm. Acesso em: 16 jun. 2020.

CALDART, R. S. Educação do Campo. In: CALDART, R. S. et al. Dicionário da Educação do Campo. Rio de Janeiro: Escola Politécnica de Saúde Joaquim Venâncio, São Paulo: Expressão Popular, 2012. p. 257-265.

CALDART, R. S. MST: um novo sujeito social. In: LAUREANO, D. S. O MST e a constituição: um sujeito histórico na luta pela reforma agrária no Brasil. 1. ed. São Paulo: Expressão Popular, 2007. p. 15-43.

CAMPOS, S. P. Práticas de letramento no meio rural brasileiro: a influência do movimento Sem Terra em escola pública de assentamento de reforma agrária. 2003. Tese (Doutorado em Linguística Aplicada) - Universidade Estadual de Campinas, Campinas, 2003.

DALMAGRO, S. L. A escola no contexto das lutas do MST. In: VENDRAMINI, C. R.; MACHADO, I. F. (org.). Escola e movimento social: experiências em curso no campo brasileiro. São Paulo: Expressão Popular, 2011. p. 15-43.

GRAMSCI, A. Organização da escola e da cultura. In: GRAMSCI, A. Os intelectuais e a organização da cultura. São Paulo: Cortez, 1991. p. 117-129. 
GRZYBOWSKI, C. Esboço de uma alternativa para pensar a educação no meio rural. Contexto \& Educação, v. 1, n. 4, p. 47-59, out./dez. 1991.

INSTITUTO BRASILEIRO DE GEOGRAFIA E ESTATÍSTICA. Parauapebas. 2019.Disponível em: https://www.ibge.gov.br/cidades-eestados/pa/parauapebas.html. Acesso em: 1 maio 2016.

INSTITUTO NACIONAL DE COLONIZAÇÃO E REFORMA AGRARIA. INCRA. 2000. Disponível em: http://www.incra.gov.br/pt/. Acesso em: 1 maio 2016.

INSTITUTO NACIONAL DE ESTUDOS E PESQUISAS EDUCACIONAIS ANÍSIO TEIXEIRA. Censo Escolar 2014. [Brasília, DF]: Inep, 2014. Disponível em: http://download.inep.gov.br/educacao basica/censo escolar/notas estatisticas/20 17/notas estatisticas do censo escolar 2014\%20final.pdf. Acesso em: 17 jun. 2020.

KRAWCZYK, N. Reflexão sobre alguns desafios do ensino médio no Brasil hoje. Cadernos de Pesquisa [online], v. 41, n. 144, p. 752-769, set./dez. 2011. Disponível em: https://doi.org/10.1590/S0100-15742011000300006. Acesso em: 24 maio 2016.

LAUREANO, D. S. O MST e a Constituição um sujeito histórico na luta pela reforma agrária no Brasil. São Paulo: Expressão Popular, 2007.

LUDKE, M.; ANDRÉ, M. E. D. A Pesquisa em educação: abordagem qualitativa. São Paulo: Cortez, 2003.

MÉSZÁROS, István. A educação para além do capital. São Paulo: Boitempo, 2008.

MORENO, G. S. Ação coletiva e luta pela terra no Assentamento Palmares II. 2011. Dissertação (Mestrado) - Universidade Federal do Pará, Belém, PA, 2011.

RODRIGUES, D. S.; ARAUJO, R. M. L. Trabalho, saberes sociais e identidade: a experiência de pescadores artesanais no estado do Pará. In: REUNIÃO ANUAL DA ASSOCIAÇÃO NACIONAL DE PÓS-GRADUAÇÃO E PESQUISA EM EDUCAÇÃO, 35., 2012, Recife. [Anais...]. Recife: Anped, 2012.

SAVIANI, D. Os saberes implicados na formação do educador. In: BICUDO, M. A. V.; SILVA JUNIOR, C. A. (org.). Formação do educador: dever do Estado, tarefa da Universidade. São Paulo: Ed. Unesp, 1996. p. 145-155.

SEMERARO, Giovanni. Gramsci e os novos embates da filosofia da práxis. Aparecida: SP: Ideias\&Letras, 2006.

STÉDILE, J. P.; FERNANDES, B. M. Brava gente: a trajetória do MST e a luta pela terra no Brasil. São Paulo: Fundação Perseu Abramo, 1999. 


\section{Anexo I - Caracterização dos informantes do trabalho de campo}

\begin{tabular}{|c|c|}
\hline Identificad & Descrição \\
\hline A1 & $\begin{array}{l}\text { Menino, } 18 \text { anos de idade, estudou no terceiro ano do Ensino Médio. } \\
\text { Veio do Maranhão com seus pais e irmãos quando ainda era } \\
\text { criança. Morava em Palmares desde os } 4 \text { anos de idade. Primeiro, } \\
\text { veio seu pai para Palmares, que fazia parte do MST, e logo } \\
\text { conseguiu um lote para construir a casa e trouxe o restante da } \\
\text { família. }\end{array}$ \\
\hline A3 & $\begin{array}{l}\text { Menino, } 17 \text { anos, nasceu no Paraná e veio para Palmares em 2014; } \\
\text { filho de trabalhador que veio para o Pará em busca de emprego. Sua } \\
\text { família "morava na roça", como ele diz, no interior de Palmares. }\end{array}$ \\
\hline A4 & $\begin{array}{l}\text { Menino, } 16 \text { anos, morava em Palmares há } 11 \text { meses. Veio do estado } \\
\text { do Amapá para Palmares para estudar na Escola Crescendo na } \\
\text { Prática. Segundo ele, a sua ida para o assentamento se deu pelo } \\
\text { interesse em participar do Movimento e estudar. }\end{array}$ \\
\hline A2 & $\begin{array}{l}\text { Menina, } 17 \text { anos, estudava na Escola Crescendo na Prática. Seus } \\
\text { pais vieram do estado do Maranhão para trabalhar. Segundo ela, } \\
\text { eles ajudaram a fundar o assentamento Palmares II. }\end{array}$ \\
\hline A5 & $\begin{array}{l}\text { Menina, } 18 \text { anos, nasceu no Maranhão, Barra do Corda, e veio ainda } \\
\text { criança para Parauapebas. Seu pai veio primeiro, em busca de } \\
\text { trabalho, e logo depois mandou dinheiro para que o resto da família } \\
\text { viesse para Parauapebas: mãe e duas filhas. }\end{array}$ \\
\hline $\begin{array}{l}\text { Coordenad } \\
\text { or }\end{array}$ & $\begin{array}{l}\text { Formação em Letras e pós-graduação em Gestão e Orientação } \\
\text { Escolar e também em Artes e Linguagem nas Escolas. Trabalha na } \\
\text { escola há } 11 \text { anos, exercendo funções tanto no município como no } \\
\text { estado. No que diz respeito a seus vínculos trabalhistas, no } \\
\text { município, é concursado, e no estado, é contratado. }\end{array}$ \\
\hline $\begin{array}{c}\text { Professor } \\
1\end{array}$ & $\begin{array}{l}\text { Formação em Filosofia e Teologia e especialização em História da } \\
\text { Filosofia e Educação do Campo. Oriundo de Fortaleza, veio para } \\
\text { Parauapebas em 1991, onde trabalhou na Escola Eduardo Angelim. } \\
\text { Ficou de } 1991 \text { a } 2001 \text { trabalhando indiretamente com os assentados } \\
\text { do MST. Desde as primeiras turmas do Ensino Fundamental na } \\
\text { Escola Crescendo na Prática, o professor estava presente. }\end{array}$ \\
\hline $\begin{array}{c}\text { Professor } \\
2\end{array}$ & $\begin{array}{l}\text { Formação em Ciências Sociais, Sociologia. Trabalhava há dois anos } \\
\text { na Escola Crescendo na Prática. Não participa do MST e tampouco } \\
\text { conhece a realidade do movimento. }\end{array}$ \\
\hline
\end{tabular}

